\title{
Development of a kinetic model for elemental sulfur and sulfate formation from the autotrophic sulfide oxidation using respirometric techniques
}

\author{
Armando Gonzalez-Sanchez*, Maria Tomas**, Antoni David Dorado**, Xavier Gamisans**, Albert \\ Guisasola*, Javier Lafuente* and David Gabriel* \\ * Department of Chemical Engineering. Universitat Autònoma de Barcelona. Edifici Q. Campus de Bellaterra. \\ 08193 Bellaterra, Barcelona, Spain \\ ** Department of Mining Engineering and Natural Resources, Universitat Politècnica de \\ Catalunya, Bases de Manresa 61-73, 08240 Manresa, Spain
}

\begin{abstract}
A kinetic model for the elemental sulfur and sulfate production from the autotrophic sulfide oxidation has been proposed. It is based on two kinetic equations able to describe the simultaneous microbial consumption of oxygen and sulfide (OUR and $S U R)$ as a function of a particular sulfideoxidizing microorganism or its physiological state, these can be characterized by the assessment of their kinetic constants. The respirometric technique allowed to estimate the dynamic experimental $O U R$ and $S U R$ profiles, which were used to calibrate the kinetic model. The ratio $O U R / S U R$ was proposed to predict the sulfide oxidation extent and then the fate of sulfide to elemental sulfur and sulfate.
\end{abstract}

Keywords Sulfide oxidation, elemental sulfur, sulfate, respirometry, kinetic model

\section{INTRODUCTION}

Gaseous hydrogen sulfide $\left(\mathrm{H}_{2} \mathrm{~S}\right)$ can induce diverse problems from unpleasant malodors up to toxicity at high concentrations. Its distinct rotten eggs smell can be detected in air at levels lower than $5 \mathrm{ppb}_{\mathrm{v}}$. It is contained in a variety of gases such as biogas, which is produced at waste water and solid waste treatment plants. Biogas is considered as a non-fossil fuel and it can contain significant concentrations of $\mathrm{H}_{2} \mathrm{~S}$ (up to $2 \% \mathrm{v} / \mathrm{v}$ ) and other sulfur species. If biogas is burned without any sulfur cleaning process both the combustion equipment and the atmosphere can be damaged. Thus, desulfurization processes with minimum impact to the environment and a simultaneous economical feasibility are needed. Biological treatments have showed to comprise these requirements, and mainly biofilters and biotrickling filters, which are widely used for $\mathrm{H}_{2} \mathrm{~S}$ control (Smet et al. 1998; Janssen et al. 2001; Gabriel and Deshusses 2003).

In biotreatment processes, gaseous $\mathrm{H}_{2} \mathrm{~S}$ is first absorbed into an aqueous scrubbing solution or an attached biofilm where sulfide $\left(\mathrm{H}_{2} \mathrm{~S}\right)$ is then converted by autotrophic aerobic sulfide-oxidizing microorganisms to non-volatile species manly elemental sulfur (equation 1) and/or sulfate (equation 2) depending on the availability of dissolved oxygen (Janssen et al. 1995).

$$
\begin{aligned}
& \mathrm{H}_{2} \mathrm{~S}+1 / 2 \mathrm{O}_{2} \rightarrow \mathrm{S}^{\mathrm{O}}+\mathrm{H}_{2} \mathrm{O} \\
& \mathrm{H}_{2} \mathrm{~S}+2 \mathrm{O}_{2} \rightarrow \mathrm{SO}_{4}{ }^{2-}+2 \mathrm{H}^{+}
\end{aligned}
$$

If high concentrations of $\mathrm{H}_{2} \mathrm{~S}$ are attempted to treat into a biotricking filter using just oxygen from air as electro acceptor, the low oxygen transfer rate can limit the $\mathrm{H}_{2} \mathrm{~S}$ removal process by undesirable partial oxidation to elemental sulfur, which can clog of the scrubbing bed deriving in some transport limitations. Additionally an excessive accumulation of dissolved sulfide into the liquid phase can be derived, thus microorganism can be inhibited leading to a process complete failure. 
Biological treatments are effective when an adapted sulfide-oxidizing consortium is used, but its diversity and activity can depend of its origin and the surrounded environmental conditions as $\mathrm{pH}$, temperature and ion strength. Visser et al. (1997) showed that the oxidation capacity and product selectivity can be strain-dependent for the autotrophic and aerobic sulfide oxidation. They found that the maximum electron transporting capacity of the microorganism is related to this dependence. In that way, if the maximum oxidative capacity is overfull by sulfide loading, then elemental sulfur can be produced. In some sulfide oxidizing microorganisms, the elemental sulfur can be either excreted out (thiobacillus) or accumulated (thiotrix) as globules inside the cell. The later can influence the further elemental sulfur oxidation to sulfate. Development of kinetic expressions for the autotrophic sulfide oxidation able to describe the sulfide and oxygen consumption rates as well as their fate is desirable to involve these expressions into a general model for an adequate design and optimization of a biological $\mathrm{H}_{2} \mathrm{~S}$ removal process. Nowadays, there is not any report that describes the kinetic production of elemental sulfur and/or sulfate from the autotrophic sulfide oxidation.

On the other hand, the respirometric technique has showed to be a very efficient tool for kinetic parameter estimation in the field of waste water treatment (Guisassola et al. 2005). It consists in the monitoring of the dissolved oxygen depletion derived from the consumption of substrate pulses in a stirred reactor with continuous aeration. Then after the fitting of the experimental data to kinetic expressions, a complete description of the physiological state of microorganism can be assessed.

Then, the aim of this work was to assess a kinetic model for the autotrophic and aerobic sulfide oxidation able to describe the sulfate and/or elemental sulfur formation, taking into account both $\mathrm{H}_{2} \mathrm{~S}$ and $\mathrm{O}_{2}$ as limiting substrates. The calibration and validation of the model was performed by the usage of the respirometry.

\section{MATERIALS AND METHODS}

\section{Microorganisms}

An enriched aerobic sulfide-oxidizing microbial consortium was used. It was obtained from a biotricking filter operated for 1 year at high $\mathrm{H}_{2} \mathrm{~S}$ concentrations under neutral $\mathrm{pH}$ conditions (Fortuny et al. 2007). The enriched microbial culture was grown under fed-batch regime in a $1.1 \mathrm{~L}$ stirred reactor under controlled conditions of $\mathrm{pH}$, temperature, aeration and agitation speed of 7.0, $25{ }^{\circ} \mathrm{C}, 0.6 \mathrm{vvm}$ and $250 \mathrm{rpm}$, respectively, where no oxygen limitation was allowed. The $\mathrm{pH}$ was controlled by automatic addition of $\mathrm{NaOH} 1 \mathrm{M}$. The composition of the mineral medium $\left(\mathrm{g} \mathrm{L}^{-1}\right)$ was; $\mathrm{NH}_{4} \mathrm{Cl}$ (1); $\mathrm{KH}_{2} \mathrm{PO}_{4},(1) ; \mathrm{K}_{2} \mathrm{HPO}_{4}$, (1); $\mathrm{NaHCO}_{3}$ (1.0); $\mathrm{MgCl} \bullet 6 \mathrm{H}_{2} \mathrm{O}$, (0.4); $\mathrm{CaCl}_{2}$, (0.25); trace elements (Pfenning et al. 1981), $1 \mathrm{~mL} \mathrm{~L}^{-1}$, and using sulfide $\left(50 \mathrm{mmol} \mathrm{L}^{-1}\right)$ as energy source.

\section{Respirometric technique}

Experimental procedure. The respiration rates were measured in a well-mixed batch reactor $\left(\mathrm{V}_{\mathrm{L}}=\right.$ $0.3 \mathrm{~L})$ continuously supplied with an air flow $\left(F_{\text {air }}=1.1 \mathrm{~L}_{\text {air }} \mathrm{h}^{-1}\right)$ regulated with a digital mass-flow controller (Bronlhorst, NL), namely LFS respirometer (Guisassola et al. 2005). The temperature was kept at $30^{\circ} \mathrm{C}$. The LFS respirometer was fitted with a polarographic oxygen electrode (CellOx 325 , WTW) with a response time of $90 \%$ in $<10 \mathrm{~s}$, and a sulfide ion selective electrode using a $\mathrm{Ag} / \mathrm{AgCl}$ electrode as reference (Thermo SympHony 14002-790, Thermo Electron Co.). Both online data of dissolved oxygen and sulfide concentrations were monitored in a PC with home-made data acquisition software. Sulfate were analyzed by ICS-1000 Ion Chromatography system with an IonPac AS9-HC column (Dionex Corporation). 
The respirometric experiments started with the addition of active and washed cells (harvested from a continuous culture) to the LFS respirometer, after the endogenous oxygen uptake rate $\left(O U R_{E N D}\right)$ and overall oxygen gas-liquid mass transfer $\left(K_{L} a\right)$ were estimated in agreement with (Guisassola $e t$ al. 2005). Then, a pulse of concentrated sulfide $\left(300 \mathrm{mmol} \mathrm{L}^{-1}\right)$ is added to obtain initial sulfide concentrations that ranged from 0.1 to $1.00 \mathrm{mmol} \mathrm{L}^{-1}$. The initial biomass concentration $\left(X_{\text {in }}\right)$ inside the respirometer was around $0.18 \mathrm{~g}_{\mathrm{Prot}} \mathrm{L}^{-1}$ in all experiments. During respirometric experiments, the composition of the buffered mineral medium used $\left(\mathrm{g} \mathrm{L}^{-1}\right.$ ) contained $\mathrm{NH}_{4} \mathrm{Cl}$, (1); $\mathrm{KH}_{2} \mathrm{PO}_{4}$, (2.9); $\mathrm{K}_{2} \mathrm{HPO}_{4},(5.0) ; \mathrm{NaHCO}_{3}(1.0) ; \mathrm{MgCl} \cdot 6 \mathrm{H}_{2} \mathrm{O},(0.1)$; the buffer capacity (ion strength $=50 \mathrm{mmol} \mathrm{L}^{-1}$ ) was enough to maintain the $\mathrm{pH}$ constant in a value of 7 . As sulfide can be stripped due to the continuous aeration, an abiotic operation of the LFS respirometer was performed to estimate the time-depended sulfide concentration profile and the overall sulfide gas-liquid mass transfer coefficient $\left(K_{L} a_{H 2 S}\right)$.

Data processing. After the experimentation stage, the collected data were processed to calculate the experimental Oxygen Uptake Rate $(O U R)$ and Sulfide Uptake Rate $(S U R)$ profiles from oxygen and sulfide mass balances in the LFS respirometer (equations 3 to 5), details are described in (Guisassola et al. 2005).

Sulfide mass balance into the LFS respirometer

Gas phase (stripping)

$$
\begin{aligned}
& \frac{d H_{2} S_{(g)}}{d t}=\frac{V_{L}}{V_{G}} \cdot K_{L} a_{H_{2} S} \cdot\left[\left(\frac{S_{H_{2} S}}{1+10^{[\mathrm{pH}-\mathrm{pK} 1]}+10^{[2 \cdot \mathrm{pH}-(\mathrm{pK} 1+\mathrm{pKK} 2)]}}\right)-\frac{H_{2} S_{(g)}}{H e}\right]-\left(\frac{F_{\text {air }}}{V_{G}} \cdot H_{2} S_{(g)}\right) \\
& t=0 \quad H_{2} S_{(g)}=0
\end{aligned}
$$

Liquid phase

$$
\begin{aligned}
& \frac{d S_{H_{2} S}}{d t}=-\left[1+10^{[\mathrm{pH}-\mathrm{pK} 1]}+10^{[(2 \cdot \mathrm{pH}-(\mathrm{pKK} 1+\mathrm{pK} 2)]}\right] \cdot K_{L} a_{H_{2} S} \cdot\left[\left(\frac{S_{H_{2} S}}{\left.1+10^{\left[\mathrm{pH}-\mathrm{pK} \mathrm{K}_{1}\right]}+10^{\left[\left(2 \cdot \mathrm{pH}-\left(\mathrm{pK} \mathrm{K}_{1}+\mathrm{pK}_{2}\right)\right]\right.}\right)}\right)-\frac{H_{2} S_{(g)}}{H e}\right]-S U R \\
& t=0 \quad S_{H_{2} S}=S_{H_{2} S \text { in }}
\end{aligned}
$$

Oxygen mass balance into the LFS respirometer

$\frac{d S_{O}}{d t}=K_{L} a \cdot\left(S_{O} *-S_{O}\right)-O U R_{E N D}-O U R$

$t=0 \quad S_{O}=S_{\text {Oin }}$

See nomenclature section below.

\section{Kinetic model}

The proposed kinetic model for the aerobic and autotrophic sulfide oxidation is based on some general assumptions indicated below.

- The aerobic and autotrophic sulfide oxidation produces only elemental sulfur $\left(\mathrm{S}^{0}\right)$ and/or sulfate $\left(\mathrm{SO}_{4}{ }^{2-}\right)$ in agreement with equations 1 and 2 , where no oxygen is consumed other than the related to sulfide oxidation

- $\mathrm{S}^{0}$ and $\mathrm{SO}_{4}{ }^{2-}$ are produced by the same microbial consortium

- The microbial consortium uses the energy derived from the sulfide oxidation for maintenance, because the very low ratio substrate/biomass applied, then growth is neglected

- The microbial consortium can be inhibited by sulfide at high concentrations

- The $S^{0}$ produced forms an homogenous suspension and it is also inert to further oxidation 
- Under acidic to neutral $\mathrm{pH}$ the chemical sulfide oxidation is neglectable compared to biological sulfide oxidation, but its effect is included into the modeled stripping process

- As a consequence of the last point, the presence of sulfite $\left(\mathrm{SO}_{3}{ }^{2-}\right)$, thiosulfate $\left(\mathrm{S}_{2} \mathrm{O}_{3}{ }^{2-}\right)$ and polysulfide $\left(\mathrm{S}_{\mathrm{x}}{ }^{2-}\right)$ are considered neglectable due to its disproportionation to sulfide or sulfate depending of surrounded redox potential (Gonzalez-Sanchez et al. 2007)

- The sulfide oxidizing activity $(S U R)$ depends on the sulfide concentration, on the oxidizing activity $(O U R)$ and on the product selectivity.

- The $O U R / S U R$ ratio defines the sulfide oxidation extent.

A kinetic model for the autotrophic and aerobic sulfide oxidation is proposed and showed in equations 6 and 7. The model describes the oxidative activity of the microorganisms based on the aerobic respiration rates, which include both dissolved sulfide and oxygen concentrations as limiting substrates. The $S U R$ is described by a power equation (Nielsen et al. 2006) with respect to sulfide, including also the oxidizing activity $(O U R)$. Since $S U R$ depends on the product selectivity, unknown at this stage of the work, the usage of power equation overcomes this limitation.

$$
\begin{aligned}
& O U R=O U R_{\max } \cdot\left(\frac{S_{H_{2} S}}{K_{S}+S_{H_{2} S}+\frac{S_{H_{2} S}^{2}}{K_{i}}}\right)\left(\frac{S_{O}}{K_{O}+S_{O}}\right) \\
& S U R=\frac{O U R}{C} S_{H_{2} S}^{b}
\end{aligned}
$$

where $S_{\mathrm{H}_{2} \mathrm{~S}}$ and $S_{\mathrm{O}}$ represent the dissolved sulfide and oxygen concentrations, $O U R_{\max }, K s, K i$, and $K o$ are the maximum specific $O U R$, the sulfide saturation constant, the sulfide inhibition constant and the oxygen saturation constant. $C$ and $b$ represent an overall oxygen/sulfide molar yield and the biological reaction order with respect to sulfide (Nielsen et al. 2006). The parameters of the kinetic model were estimated fitting the experimental $O U R$ and $S U R$ profiles with the corresponding experimental sulfide and oxygen concentrations.

\section{Prediction of elemental sulfur and sulfate production rates}

The $O U R$ based model indicated above (equations 6 and 7) can predict the sulfide oxidation rates at given $S_{\mathrm{H}_{2} \mathrm{~S}}$ and $S_{\mathrm{O}}$, but no the fate of sulfide. To distinguish that, we considered that elemental sulfur and sulfate are the only products from the aerobic sulfide oxidation under acidic and neutral conditions (Janssen et al. 1995) and the $O U R / S U R$ ratio defines the sulfide oxidation extent, then equation 8 to 10 can be applied.

$$
\begin{aligned}
& S^{0} P R+S O_{4}^{2-} P R=S U R \\
& {\left[\frac{S^{0} P R}{S U R}\right]+\left[\frac{S O_{4}^{2-} P R}{S U R}\right]=f_{S^{0}}+f_{S O_{4}^{2-}}=1} \\
& {\left[\frac{O U R}{S U R}\right]=D \cdot \frac{S O_{4}^{2-} P R}{S^{0} P R}=D \cdot \frac{f_{S O_{4}^{2-}}}{f_{S^{0}}}}
\end{aligned}
$$

where $S^{0} P R$ and $S_{4}{ }^{2-} P R$ represent the elemental sulfur and sulfate production rates, $f_{S^{0}}$ and $f_{S O_{4}^{2-}}$ represent the sulfide molar fraction oxidized to elemental sulfur and sulfate, $D$ represents a 
proportionality constant. Substituting equation 11 into 10 then equation 12 is obtained.

$$
\begin{aligned}
& f_{S^{0}}=1-f_{S O_{4}^{2-}} \\
& f_{S O_{4}^{2-}}=\frac{\left[\frac{O U R}{S U R}\right]}{D+\left[\frac{O U R}{S U R}\right]}
\end{aligned}
$$

The product selectivity of the aerobic sulfide oxidation is expressed in terms of the $O U R / S U R$ ratio computed at each $S_{\mathrm{H}_{2} \mathrm{~S}}$ and $S_{O}$. Thus, the elemental sulfur and sulfate mass balances into the LFS respirometer can be easily expressed by equations 13 and 14 respectively.

$$
\begin{aligned}
& \frac{d S_{S^{0}}}{d t}=\left(1-f_{S O_{4}^{2-}}\right) \cdot S U R \\
& t=0 ; S_{S^{0}}=0 \\
& \frac{d S_{S O_{4}^{2-}}}{d t}=f_{S O_{4}^{2-}} \cdot S U R \\
& t=0 ; \quad S_{S O_{4}^{2-}}=0
\end{aligned}
$$

\section{RESULTS AND DISCUSSION}

\section{Performance of the respirometric technique}

The respirometric technique was implemented to study the sulfide oxidation under autotrophic and aerobic conditions. The use of the LFS respirometer allowed controlling the dissolved oxygen concentration under either limiting or no limiting conditions.

Under no oxygen limiting conditions, where continuous aeration was performed, a prior abiotic operation of the LFS respirometer was needed in order to estimate the overall gas-liquid mass transfer coefficients for oxygen $\left(K_{L} a\right)$ and sulfide $\left(K_{L} a_{H_{2} S}\right.$ ), which resulted to be $6.5 \mathrm{~h}^{-1}$ and $1.2 \mathrm{~h}^{-}$ ${ }^{1}$, respectively. For the estimation of the half-saturation constant for oxygen $(K o)$, oxygen limiting conditions were required, which were reached by stopping the aeration. Since also little oxygen transfer occurs between the gaseous head space and the surface of the liquid, which effect becomes more important when very low oxygen concentrations were attained (maximum oxygen gradient) as a consequence of the biological consumption, then also abiotic experiments were conducted for the estimation of the superficial overall mass transfer coefficient for oxygen $\left(K_{L} a^{\text {sup }}\right)$, which resulted to be $1.4 \mathrm{~h}^{-1}$.

After the physical characterization of the LFS respirometer, biotic experiments were conducted. Figure 1(a) shows typical dissolved oxygen and sulfide concentration profiles induced after addition of a sulfide pulse. The initial sulfide concentration was $0.8 \mathrm{mmol} \mathrm{L}^{-1}$. The computed experimental $O U R$ and $S U R$ profiles are showed in figure 1(b). After the sulfide pulse addition, the $S U R$ was initially much higher than the $O U R$, indicating that the maximum oxidative capacity of the microbial consortium was overfull by instantaneous excess of sulfide. Then, elemental sulfur could be produced. From minute 100 to 123 , the $O U R$ increased slightly up to maximum value, probably due to the decrease of the sulfide inhibition. Afterwards, both SUR and $O U R$ decreased because of 
sulfide limitation. According to the abovementioned hypothesis, figure 1(c) would indicate the sulfide oxidation extent. Thus, before minute 123 the main sulfide oxidation product must be elemental sulfur and sulfate thereafter. The evaluation of the $O U R / S U R$ ratio as control parameter for the sulfide oxidation extent has been previously reported (Janssen et al. 1997, Alcantara et al. 2004 and Gonzalez-Sanchez et al. 2005) but restricted under the assumption of steady-state condition.
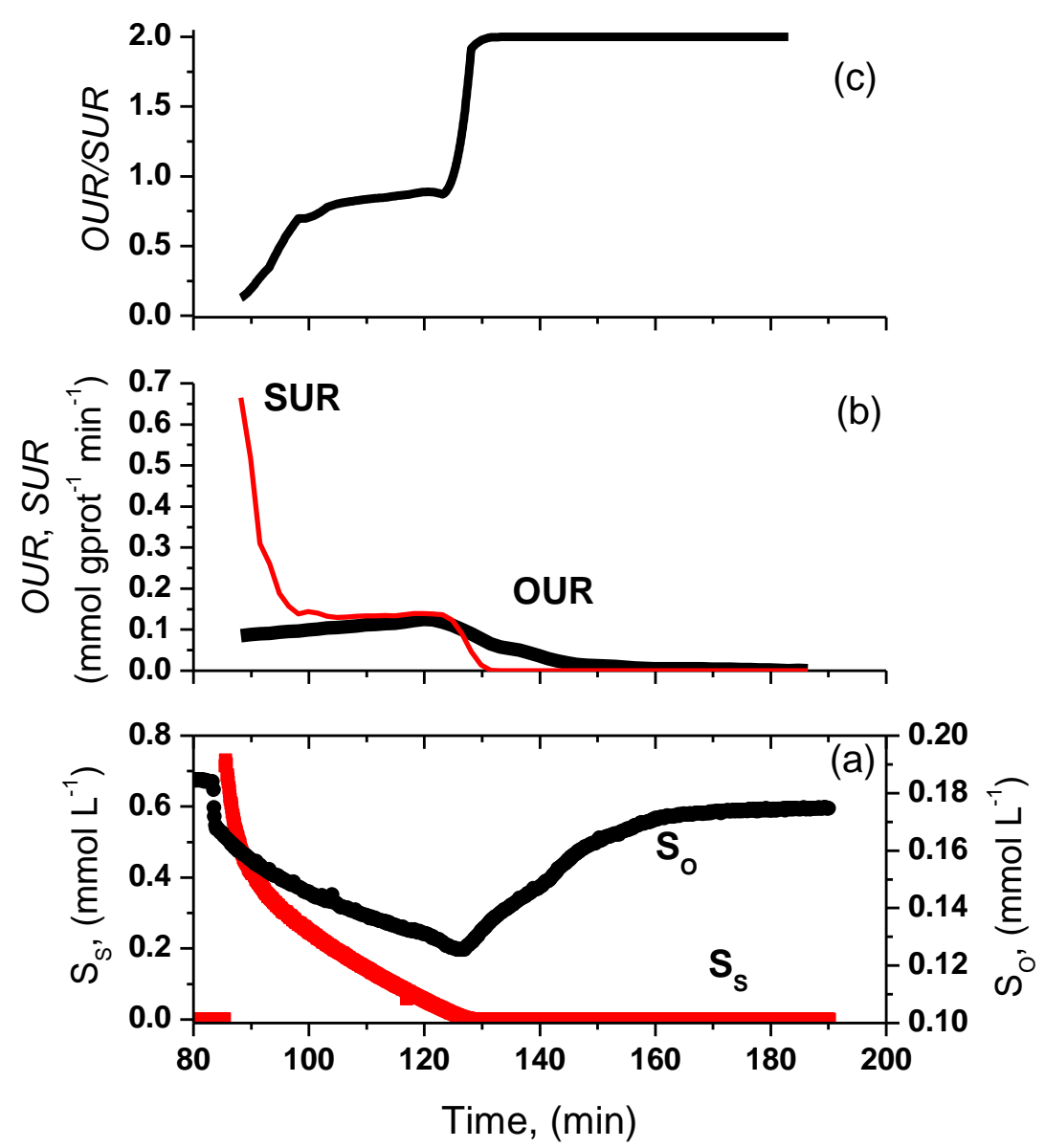

Figure 1. Performance of the LFS respirometer after a sulfide pulse addition.

$\left(S_{\text {in }}=0.8 \mathrm{mmol} \mathrm{L}^{-1}, X_{\text {in }}=0.15 \mathrm{~g}_{\text {Prot }} \mathrm{L}^{-1}, F_{\text {air }}=1.1 \mathrm{~L} \mathrm{~h}^{-1}, K_{L} a=6.5 \mathrm{~h}^{-1}, K_{L} a_{H 2 S}=1.2 \mathrm{~h}^{-1}\right)$

(a) Oxygen and sulfide concentration profiles, (b) experimental $O U R$ and $S U R$ profiles and (c) experimental $O U R / S U R$ ratio; computed from equations 3 to 5.

\section{Parameters estimation of the kinetic model}

The experimental $O U R$ profiles were fitted to the $O U R$ model (equation 6) as shown in figure 2(a), assuming no oxygen limitation, the parameters of the Monod-Haldane type kinetics and the $O U R_{\max }$. were obtained The values estimated were, $O U R_{\max }$ of $0.12 \pm 0.01 \mathrm{mmol} \mathrm{O} \mathrm{gProt}^{-1} \mathrm{~min}^{-1}$, the affinity constant $K$ s of $0.001 \pm 0.0006 \mathrm{mmol} \mathrm{S} \mathrm{L}^{-1}$ and the inhibition constant $K i$ of 1.015 \pm 0.512 . Visser et al. (1997) reported a higher $O U R_{\max }$ value for specialized sulfide oxidizing strains (Thiobacillus sp. strain W5 and Thiobacillus neapolitanus) around $2 \mathrm{mmol} \mathrm{O}_{2} \mathrm{gProt}^{-1} \mathrm{~min}^{-1}$. Van Gemerden reported an inhibitory effect on sulfide phototrophic oxidizing bacteria of $K i=2$ to 4 mmol L ${ }^{-1}$.

Similarly, the $O U R$ assessment under oxygen limitation was performed allowing a complete oxygen depletion while keeping a sulfide concentration around $0.01 \mathrm{mmol} \mathrm{L}^{-1}$ where the $O U R$ showed to be 
optimal (Figure 2a). Figure 2(b) shows the best fitting for experimental oxygen concentrations with the corresponding experimental $O U R$ profiles, using the Monod type model. The values estimated were $O U R_{\max }$ of $0.11 \mathrm{mmol} \mathrm{O}_{2} \mathrm{gProt}^{-1} \mathrm{~min}^{-1}$ with a $K_{\mathrm{O}}$ of $0.028 \pm 0.006 \mathrm{mmol} \mathrm{O}_{2} \mathrm{~L}^{-1}$.
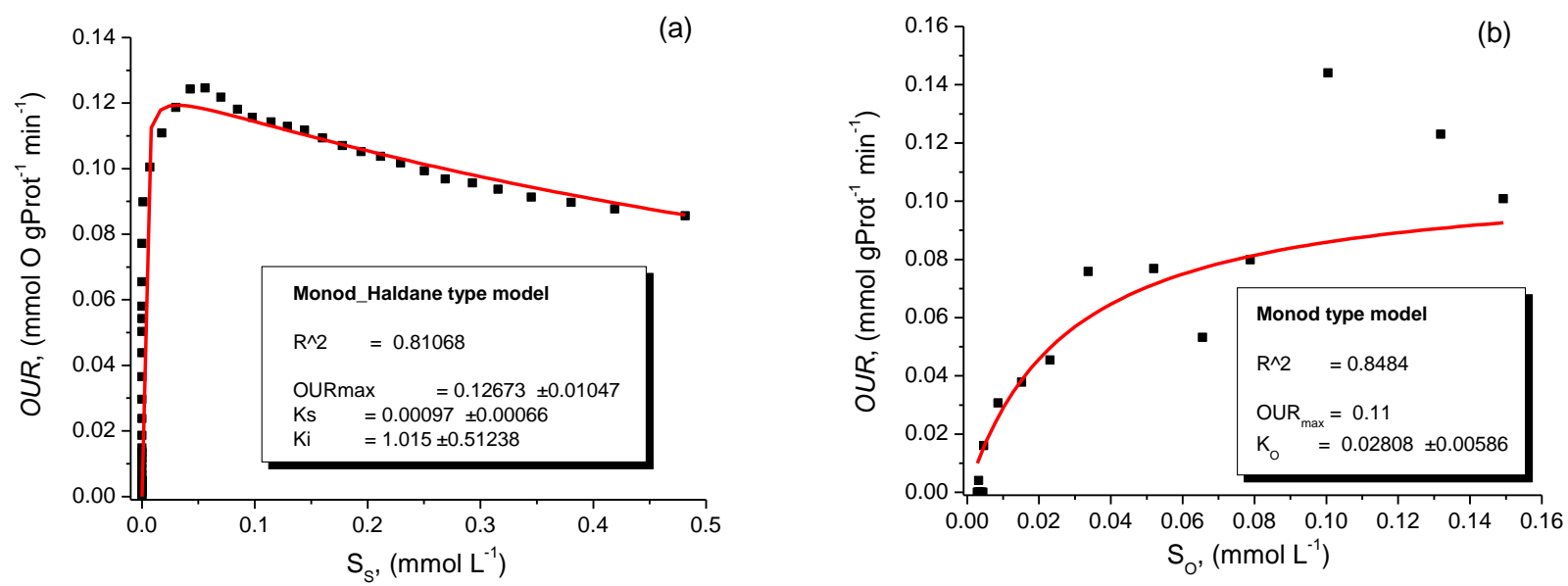

Figure 2. Parameter estimation of the equation 6, using the experimental $O U R$ profiles and their corresponding sulfide and oxygen concentrations.

Figure 3(a) shows the best fitting of the experimental data to equation7. Resulted values for $b$ and $C$ were $0.17 \pm 0.01$ and $0.55 \pm 0.025\left(\mathrm{mmol} \mathrm{O}_{2} \mathrm{~L}^{-1}\right)\left(\mathrm{mmol} \mathrm{S} \mathrm{L}^{-1}\right)^{-0.84}$ respectively. The parameter $C$ could be interpreted as the ability of the microorganism to produce elemental sulfur, where a value of 0.5 indicate that the microorganism can transform all oxidized sulfide to elemental sulfur. The experimental data generated from the performance of the respirometric technique, showed to fit well to the kinetic model proposed, showing a regression coefficient greater than 0.81 in all cases. Even if further experimental data is needed for model validation, the predicted values for elemental sulfur and sulfate production shown in figure 3(b) resulted to be reasonable in terms of the amount and type of sulfur produced during the respirometry experiments used for model calibration. The best fitting for the calibration of the product model was $D=0.65$. Finally, Table 1 shows a summary of the estimated data for the microbial consortium considered according to the calibration experiments performed.
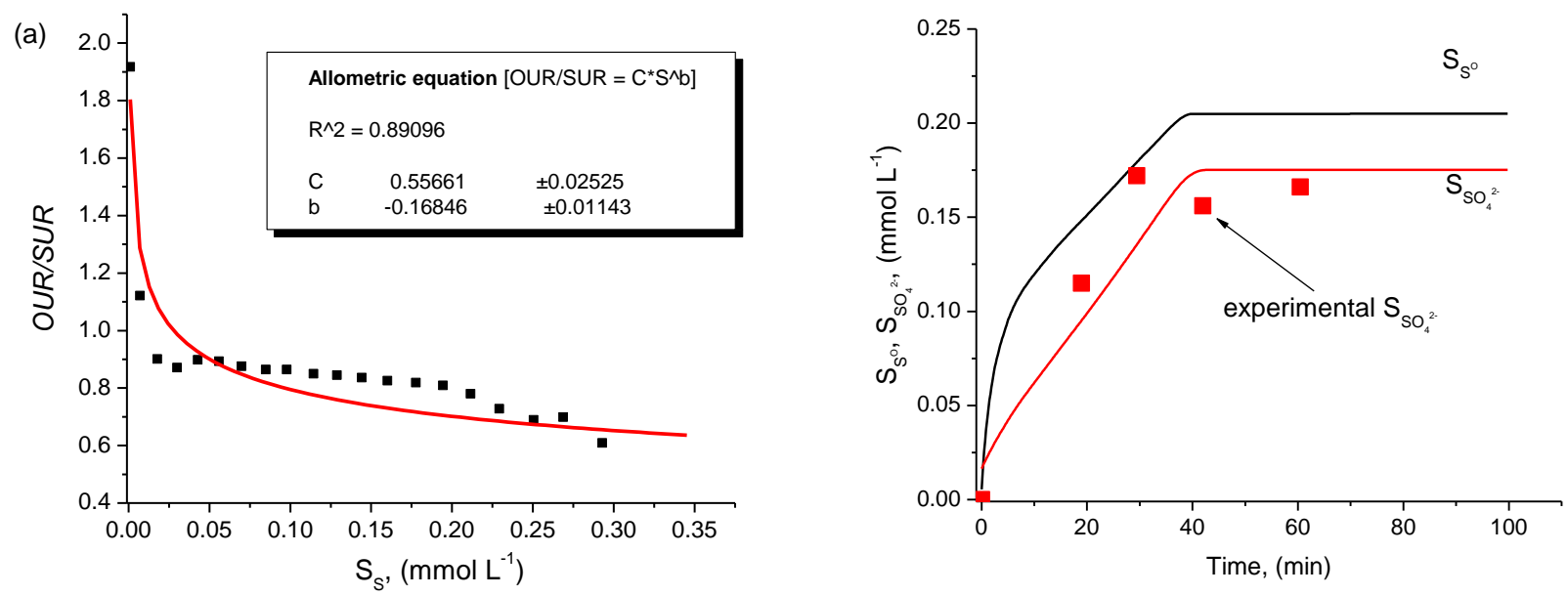

Figure 3 Model predictions after a sulfide pulse addition $\left(S_{\text {in }}=0.8 \mathrm{mmol} \mathrm{L} \mathrm{L}^{-1}, X_{\text {in }}=0.15 \mathrm{~g}_{\text {Prot }} \mathrm{L}^{-1}\right.$, $F_{\text {air }}=1.1 \mathrm{~L} \mathrm{~h}^{-1}, K_{L} a=6.5 \mathrm{~h}^{-1}, K_{L} a_{H 2 S}=1.2 \mathrm{~h}^{-1}$ ) (a) Parameter estimation of the equation 7 , using the experimental $O U R / S U R$ ratio profiles and their corresponding experimental sulfide concentrations.

(b) Elemental sulfur and sulfate predicted by the model 
Table 1. Summary of the kinetic parameters estimated during a respirometric experiment

\begin{tabular}{lll}
\multicolumn{2}{l}{$\left(S_{\text {in }}=0.8 \mathrm{mmol} \mathrm{L}\right.$} \\
Parameter & $\left.X_{\text {in }}=0.15 \mathrm{~g}_{\text {Prot }} \mathrm{L}^{-1}, F_{\text {air }}=1.1 \mathrm{~L} \mathrm{~h}^{-1}, K_{L} a=6.5 \mathrm{~h}^{-1}, K_{L} a_{H 2 S}=1.2 \mathrm{~h}^{-1}\right)$ \\
\hline$O U R_{\max }$ & Value & Units \\
$K_{S}$ & $0.127 \pm 0.01$ & $\mathrm{mmol} \mathrm{O}_{2} \mathrm{~g}_{\text {Prot }}{ }^{-1} \mathrm{~min}^{-1}$ \\
$K i$ & $0.001 \pm 0.0006$ & $\mathrm{mmol} \mathrm{S} \mathrm{L}^{-1}$ \\
$K_{O}$ & $1.015 \pm 0.512$ & $\mathrm{mmol} \mathrm{S} \mathrm{L}^{-1}$ \\
$C$ & $0.028 \pm 0.006$ & $\mathrm{mmol} \mathrm{O}_{2} \mathrm{~L}^{-1}$ \\
$b$ & $0.556 \pm 0.02$ & $\left(\mathrm{mmol} \mathrm{O}_{2} \mathrm{~L}^{-1}\right)\left(\mathrm{mmol} \mathrm{S} \mathrm{L}^{-1}\right)^{-0.84}$ \\
\hline$D$ & $0.168 \pm 0.01$ & -- \\
\hline
\end{tabular}

\section{CONCLUSIONS}

The kinetic model proposed for autotrophic sulfide oxidation resulted to be reasonable for the prediction of the $O U R$ and $S U R$ profiles and, probably, of the elemental sulfur and sulfate amounts produced. The values of the biokinetic parameters for the microbial consortium tested were in the same order of magnitude than the commonly reported for neutrophilic microorganism, but the value of $O U R_{\max }$ was much lower than the reported for specialized sulfide oxidizing strains, which indicate that further efforts have to be made in order to improve the sulfide oxidizing activity of the microbial consortium.

\section{NOMENCLATURE}

$f_{S^{0}} \quad$ molar sulfide fraction oxidized to elemental sulfur

$f_{\mathrm{SO}_{4}^{2-}} \quad$ molar sulfide fraction oxidized to sulfate

A stoichiometric oxygen/sulfide ratio to elemental sulfur $\left(\mathrm{mmol} \mathrm{O}_{2}(\mathrm{mmol} \mathrm{S})^{-1}\right)$

$b \quad$ biological reaction order with respect to sulfide

B stoichiometric oxygen/sulfide ratio to sulfate $\left(\mathrm{mmol} \mathrm{O}_{2}(\mathrm{mmol} \mathrm{S})^{-1}\right)$

$C \quad$ oxygen/sulfide molar yield $\left(\left(\mathrm{mmol} \mathrm{O}_{2} \mathrm{~L}^{-1}\right)\left(\mathrm{mmol} \mathrm{S} \mathrm{L}^{-1}\right)^{b-1}\right)$

$F_{\text {air }} \quad$ volumetric air flow rate $\left(\mathrm{L}_{\text {gas }} \mathrm{h}^{-1}\right)$

$\mathrm{H}_{2} \mathrm{~S}_{(\mathrm{g})} \quad$ gaseous hydrogen sulfide concentration, (mmol $\mathrm{H}_{2} \mathrm{~S} \mathrm{~L}_{\mathrm{gas}}{ }^{-1}$ )

$\mathrm{He} \quad$ sulfide Henry constant $\left(0.41\left[\mathrm{mmol} \mathrm{L}^{-1}\right]_{\text {gas }} /\left[\mathrm{mmol} \mathrm{L}^{-1}\right]_{\text {líq }}\right)$

$K_{i} \quad$ sulfide inhibition constant $\left(\mathrm{mmol} \mathrm{S} \mathrm{L}^{-1}\right)$

$K_{L} a \quad$ overall gas-liquid mass transfer coefficient for oxygen $\left(\mathrm{h}^{-1}\right)$

$K_{L} a^{\text {sup }} \quad$ superficial overall gas-liquid mass transfer coefficient for oxygen $\left(\mathrm{h}^{-1}\right)$

$K_{L} a_{H 2 S} \quad$ overall gas-liquid mass transfer coefficient for hydrogen sulfide $\left(\mathrm{h}^{-1}\right)$

$K_{O} \quad$ oxygen saturation constant $\left(\mathrm{mmol} \mathrm{O}_{2} \mathrm{~L}^{-1}\right)$

$K_{S} \quad$ sulfide saturation constant $\left(\mathrm{mmol} \mathrm{S} \mathrm{L}^{-1}\right)$

OUR exogenous specific oxygen uptake rate $\left(\mathrm{mmol} \mathrm{O}_{2} \mathrm{~g}_{\text {prot }}^{-1} \mathrm{~min}^{-1}\right)$

$O U R / S U R$ molar consumption ratio oxygen/sulfide

$O U R_{E N D} \quad$ endogenous specific oxygen uptake rate $\left(\mathrm{mmol} \mathrm{O}_{2} \mathrm{~g}_{\text {prot }}{ }^{-1} \mathrm{~min}^{-1}\right)$

$\mathrm{pK}_{1}, \mathrm{pK}_{2} \quad$ dissociation constants for sulfide (7.1 and 13.6 respectivley)

$S_{S^{0}}$

$S^{0} P R$

$S_{H 2 S}$

$S_{H 2 S \text { in }}$

$S_{O \text { in }}$

$S_{O}$ elemental sulfur concentration $\left(\mathrm{mmol} \mathrm{S}^{0} \mathrm{~L}^{-1}\right)$ specific elemental sulfur production rate $\left(\mathrm{mmol} \mathrm{S}^{0} \mathrm{~g}_{\text {prot }}{ }^{-1} \mathrm{~min}^{-1}\right)$ dissolved sulfide concentration, ( $\mathrm{mmol} \mathrm{S} \mathrm{L}^{-1}$ ) initial dissolved sulfide concentration, $\left(\mathrm{mmol} \mathrm{S} \mathrm{L}^{-1}\right)$ initial dissolved oxygen concentration $\left(\mathrm{mmol} \mathrm{O}_{2} \mathrm{~L}^{-1}\right)$ $S_{O}^{*}$ dissolved oxygen concentration $\left(\mathrm{mmol} \mathrm{O}_{2} \mathrm{~L}^{-1}\right)$ dissolved oxygen concentration in equilibrium with oxygen in $\operatorname{air}\left(\mathrm{mmol} \mathrm{O}_{2} \mathrm{~L}^{-1}\right)$ 


$\begin{array}{ll}S_{\mathrm{SO}_{4}{ }^{2-}} & \text { sulfate concentration, }\left(\mathrm{mmol} \mathrm{SO}{ }_{4}{ }^{2-} \mathrm{L}^{-1}\right) . \\ \mathrm{SO}_{4}{ }^{2-} \mathrm{PR} & \text { specific sulfate production rates }\left(\mathrm{mmol} \mathrm{SO}_{4}{ }^{2-} \mathrm{gprot}^{-1} \mathrm{~min}^{-1}\right) \\ \mathrm{SUR} & \text { specific sulfide uptake rate }\left(\mathrm{mmol} \mathrm{S} \mathrm{g} \mathrm{prot}^{-1} \mathrm{~min}^{-1}\right) \\ \mathrm{t} & \text { time, }(\mathrm{min}) \\ V_{\mathrm{G}} & \text { gaseous head space volume of respirometer, }(\mathrm{L}) \\ V_{L} & \text { liquid volume of respirometer, }(\mathrm{L}) \\ X & \text { biomass concentration, }\left(\mathrm{g}_{\text {Prot }} \mathrm{L}^{-1}\right)\end{array}$

\section{REFERENCES}

Alcántara S., Velasco A., Muñoz A., Cid J., Revah S. and Razo-Flores E. (2004). Sulfide oxidation by a microbial consortium in a recirculation reactor system: sulfur formation under oxygen limitation and removal of phenols. Environm. Sci. Technol., 38, 918-923.

Fortuny M., Baeza J., Gamisans X., Casas C., Lafuente J., Deshusses M. and Gabriel D. (2008). Biological sweetening of energy gases mimics in biotrickling filters. Chemosphere, 71. 10-17

Fuseler, K., Cypionka, H. Elemental sulfur as an intermediate of sulfide oxidation with oxygen by Desulfobulbus propionicus (1995). Arch Microbiol.. 164, 104-109.

Gabriel, D. and Deshusses, M. A. (2003). Retrofitting existing chemical scrubbers to biotrickling filters for $\mathrm{H}_{2} \mathrm{~S}$ emission control. Proc. Natl. Acad. Sci. U.S.A. 100, 6308-6312.

Gonzalez-Sanchez A. and Revah S. (2007). The effect of chemical oxidation on the biological sulfide oxidation by an alkaliphilic sulfoxidizing bacterial consortium. Enzyme Microb. Technol., 40, 292-298.

Gonzalez-Sanchez A., Alcantara S., Razo-Flores E. and Revah, S. (2005). Oxygen transfer and consumption in a thiosulfate oxidizing bioreactor with sulfur production. Lett. Appl. Microbiol. 41, 141-146

Guisasola, A., Jubany, I., Baeza, J., Carrera, J. and Lafuente, J. (2005). Respirometric estimation of the oxygen affinity constants for biological ammonium and nitrite oxidation. J Chem Technol Biotechnol, 80, 388-396.

Janssen A., Ma S., Lens P. and Lettinga G. (1997). Performance of a sulfide-oxidizing expandedbed reactor supplied with dissolved oxygen. Biotechnol Bioeng., 53, 32-40.

Janssen A., Sleyster R., van der Kaa C., Jochemsen A., Bontsema J. and Lettinga G. (1995). Biological sulphide oxidation in a fed-bach reactor. Biotechnol. Bioeng., 47, 327-333.

Janssen, A., Ruitenberg, R., Buisman, C. (2001). Industrial applications of new sulfur biotechnology. Wat. Sci. Technol., 44, 85-90.

Nielsen, A.H., J. Vollertsen and T. Hvitved-Jacobsen. (2006). Kinetics and stoichiometry of sulfide oxidation in sewer wastewater-effects of $\mathrm{pH}$ and temperature. Water Environment Research, 78(3), 275-283.

Pfennig, N.; Lippert, K. D. Über das Vitamin B12-Bedürfnis phototropher Schwefelbacterien. (1966). Arch. Microbiol., 55, 245-256.

Smet, E.; Lens, P.; van Langenhove H. (1998).Treatment of waste gases contaminated with odorous sulfur compounds. Crit. Rev. Environ. Sci. Technol. 28, 89-117.

Van Gemerden, H. (1984). The sulfide affinity of phototrophic bacteria in relation to the location of elemental sulfur. Arch Microbiol. 139, 289-94.

Visser, J. M.; Robertson, L.; van Verseveld H. and Kuenen, J. (1997). Sulfur Production by obligately chemolithoautotrophic thiobacillus species. Appl. Env. Microbiol. 63(6), 2300-2305. 